\title{
The Evaluation of Gastrointestinal Nematodes in Faecal Samples Using Multiplex Real-Time PCR Assays
}

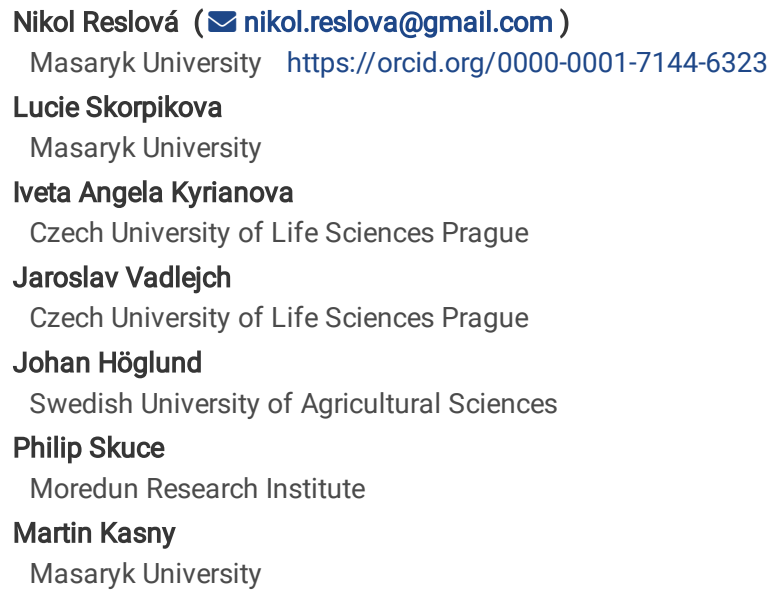

Version of Record: A version of this preprint was published at Parasites \& Vectors on August 9th, 2021. See the published version at https://doi.org/10.1186/s13071-021-04882-4. 


\section{Abstract}

Background: The diagnosis of gastrointestinal nematode (GIN) infections in ruminants is routinely based on morphological/morphometric analysis of parasite specimens recovered by coprological methods and followed by larval culture techniques. Such an approach is laborious, time-consuming, requires a skilled expert and moreover suffers from certain limitations. Molecular tools are able to overcome the majority of these issues, providing accurate identification of nematode species and, therefore, may be valuable in sustainable parasite control strategies.

Methods: Two multiplex real-time PCR assays for specific detection of six main GIN species, including an internal amplification control to avoid false negative results, were designed targeting SSU rRNA and COI genetic markers, as well as established ITS1/2 sequences. The assays were optimized for analysis of DNA extracted directly from sheep faeces and verified for Haemonchus contortus, Teladorsagia circumcincta, Trichostrongylus colubriformis, Nematodirus battus, Chabertia ovina, and Ashworthius sidemi. Semi-quantitative evaluation of infection intensity was enabled using a plasmid construct and a dilution series of sheep faeces with a known number of nematode eggs. Assays were tested on 44 individually collected faecal samples from three farms and results were compared to those from faecal egg counts (FEC) using the Concentration McMaster technique, and larval cultures (LC).

Results: Multiplex real-time PCR assays showed great specificity to target nematodes. During the analysis of faecal samples, the assays proved to have higher sensitivity in strongylid-type egg detection over FEC by revealing 3 false negative samples, while showing moderate agreement in evaluation of infection intensity. The multiplex assays further clarified GIN species identification compared to LC, which had confused determination of Teladorsagia spp. for Trichostrongylus spp.

Conclusions: Our multiplex assays proved to be a rapid and accurate approach enabling simultaneous and reliable GIN species identification from faeces and semi-quantitative estimation of the number of eggs present. This approach increases diagnostic value and may add a high degree of precision to evaluation of anthelmintic efficacy, where it is important to identify species surviving after treatment.

\section{Background}

All grazing livestock are exposed to gastrointestinal nematode (GIN) infections. The higher worm load, the greater the impact on animal health, productivity, and welfare [1]. Typically, grazing ruminants are often simultaneously infected with several species of GINs whose unique mix contributes to the sum of the clinical effects and determines severity of infections. In combination, these infections are responsible for parasitic gastroenteritis (PGE) which is a parasitic disease of major socioeconomic importance in farming communities worldwide [2]. In small ruminants, the GINs of greatest importance belong to the superfamily Trichostrongyloidea and the most important genera are Haemonchus, Teladorsagia, and Trichostrongylus [3]. To a lesser extent also members of the genus Nematodirus and Cooperia and in superfamily Strongyloidea (genera Chabertia and Oesophagostomum) commonly parasitize sheep and goats. These latter species cause disease only in exceptional circumstances but may also contribute to PGE. Nevertheless, the manifestation and severity of the disease is affected by a broad range of host-parasite related factors such as host immunity and nutrition as well as parasitic species richness and intensity of infection [4]. In general, more severe clinical manifestations, typically diarrhoea and weight loss, develop with heavier nematode burdens and anaemia associated with the blood-sucking habit of Haemonchus makes it a highly pathogenic parasite. Therefore, even regular observation of animals may not reveal the extent of parasite burden until PGE develops into a severe clinical form [2].

GIN infections in ruminant livestock are typically controlled by anthelmintic drugs [5]. However, the excessive and, in some cases, incorrect use of these chemicals has escalated over the past decades into widespread dissemination of resistant nematode populations among livestock herds and even to a high prevalence of multi-drug resistance to anthelmintics in some regions of the world [6, 7]. The situation with high GIN burdens in small ruminants, together with increasing anthelmintic drug resistance, leads us to focus our efforts towards integrated control with precisely justified and species-dependent drug use, whose cornerstone is fast and reliable diagnostics [8,9]. There is no worldwide consensus on the best sampling strategy and diagnostic procedure for GIN screening in sheep [10] but traditional coprological methods are regarded as limited and unreliable [11, 12]. From this point of view the precise diagnostics remain challenging. The limitation of conventional faecal flotation techniques is in the inability to reliably distinguish individual strongyle genera, given the fact that the morphology of the eggs is extremely similar between species (with the exception of Nematodirus spp.) [13]. For identification to genus level and beyond, time-consuming larval culture (LC) is routinely used, enabling the development of extracted eggs to third-stage larvae $\left(\mathrm{L}_{3}\right)$, which can then be microscopically differentiated based on their both morphological and morphometric characters [14]. LC has limitations related not only to different requirements for hatching and larval development of individual nematode species but also on the experience of the investigator and ambiguous taxonomic distinction $[12,15]$.

PCR-based methods have shown high sensitivity and specificity for the detection of parasite DNA, yet their use for in vivo diagnostics of GIN infections directly from faeces has so far been limited to only three studies by Höglund et al. (2019) [10], Sweeny et al. (2011) [16] and Roeber et al. (2012) [17]. The focus of GIN diagnostics using molecular methods is still mainly related to extracted eggs [11, 12, 13, 18, 19, 20, 21, 22] and/or cultivated larvae [13, 14, 22, 23]. Faecal DNA extraction is still believed to be unsuitable for usage in most subsequent PCR amplifications due to the presence of faecal inhibitors [24]. However, developments in DNA extraction procedures and application of inhibitor removal technologies have made such DNA ideal for subsequent PCR-based analyses, especially real-time PCR. This has made this technology a powerful alternative or additional tool to coproscopy [25].

In the present study, we designed two multiplex real-time PCR assays, which included internal amplification control, targeting the internal transcribed spacers 1, 2 (ITS1/2), small subunit rRNA (SSU rRNA) and cytochrome c oxidase subunit I (COI) genetic markers to diagnose naturally acquired GIN infections in sheep. We developed six specific detection systems and describe their use for the detection of genomic DNA of the nematode species Haemonchus contortus, Teladorsagia circumcincta, Trichostrongylus colubriformis, Nematodirus battus, Ashworthius sidemi, and Chabertia ovina, respectively. We further tested the functionality of both multiplex assays on 44 individual faecal samples from sheep and compared results of a semi-quantitative evaluation of infection intensity to the egg enumerations generated by a conventional faecal flotation technique. The ability to reliably identify all targeted GINs present within faeces

Page 2/15 
and rank them according to their numerical contribution in a single reaction represents a major advantage over conventional coprological techniques. This approach has clear, practical value, is cost-effective and efficient, and, hence, widely applicable in the control of parasites in ruminant livestock and epidemiological studies.

\section{Material And Methods}

Biological material. The optimization experiments were carried out with genomic DNA (gDNA) extracted from adult nematodes stored in 70\% ethanol, which were recovered from the gastrointestinal tracts of ruminants using standard post-mortem examination. The host animals came from various areas of the Czech Republic and sampling was conducted in 2017-2019. The recovered nematodes were identified based on their dominant distinguishing morphological/morphometric characters using a light microscope Olympus BX51 and measurement of their dominant morphological characteristics carried out by QuickPHOTO MICRO 3.0 software (PROMICRA). Adult nematodes were determined as H. contortus, T. circumcincta, T. colubriformis, N. battus, A. sidemi, Ch. ovina, Cooperia curticei, $C$. pectinata and Oesophagostomum columbianum. One lamb experimentally infected with $H$. contortus served as a source of eggs for accurate assessment of nematode eggs in faeces.

In total, 44 individual faecal samples for functional verification of the multiplex assays were collected rectally on three farms during the autumn of 2019 in the Czech Republic. Approximately $5 \mathrm{~g}$ of faeces from the rectum of approximately $10 \%$ of the animals in the flock were collected and stored in plastic zipper bags and after transportation frozen at $-80^{\circ} \mathrm{C}$, until further processing for molecular analyses. At the same time, another batch of $5 \mathrm{~g}$ of faeces originating from the same animals was collected for immediate quantitative coprological examination using the Concentration McMaster technique with a minimum diagnostic sensitivity of 20 strongyle eggs per gram of faeces (EPG) [26]. Besides strongylid-type egg enumeration, the presence of Nematodirus spp. eggs (includes all species except $N$. battus, which is distinguished separately) was also recorded for each sample.

In addition to coprological examination, about $1 \mathrm{~kg}$ of pooled faecal sample from the whole flock was collected at each farm and incubated under standard conditions to obtain infective $L_{3}$ larvae. Faecal pellets were mixed in a beaker with Vermiculite chips, manually homogenized and then kept in moist conditions in an incubator at $28{ }^{\circ} \mathrm{C}$ for one week. The developed $\mathrm{L}_{3} \mathrm{~s}$ were recovered using Baermannization and identified based on their morphological/morphometric features to the genus level according to morphological keys in van Wyk et al. (2004) [15] and van Wyk \& Mayhew (2013) [27].

DNA extraction. The gDNA of adult nematodes, which served as reference template DNA during the optimization experiments, was extracted from a single individual of each given nematode species using previously published protocols $[28,29]$ and based on overnight incubation at $55^{\circ} \mathrm{C}$ in $50 \mu$ of extraction buffer (100 mM Tris-HCl, 10 mM EDTA, $100 \mathrm{mM} \mathrm{NaCl}, 1 \%$ SDS, $1.5 \mathrm{mM}$ dithiothreitol) containing 0.06 mg proteinase $\mathrm{K}$, followed by alcohol precipitation. Concentration, yield, and purity of extracted gDNA were measured by NanoDrop 8000 Spectrophotometer (Thermo Fisher Scientific). Extracted gDNA was stored at $-20^{\circ} \mathrm{C}$ until processed.

Faecal samples were thawed before the extraction and each zipper bag containing sample was thoroughly manually homogenized. Out of the homogenized faeces, $1 \mathrm{~g}$ was taken for further processing and extraction using Quick-DNA Fecal Soil Microbe MiniPrep kit (Zymo Research). Each sample was placed in a sampling container and dissolved by shaking in $800 \mu$ l of BashingBead Buffer mixed with $3200 \mu \mathrm{l}$ of PBS buffer. A negative isolation control (NIC), i.e., a tube without faeces, starting from this step through the whole extraction procedure together with the samples, was included in every extraction procedure. Then, $1200 \mu \mathrm{l}$ of the sample solution was transferred into ZR BashingBead Lysis Tube and mechanically lysed, ensuring the disruption of eggs and further homogenization of other debris, in a Retsch MM200 mixer mill (RETSCH) for 10 min. Then, lysis tubes were centrifuged, and the supernatant transferred to a Zymo-Spin III-F Filter; the further procedure faithfully followed the kit's manufacturer protocol. After elution, DNA samples were $10 \times$ diluted and stored at $-20{ }^{\circ} \mathrm{C}$ until use.

Detection systems. Target gene sequences of nematode species of interest were downloaded from the NCBI GenBank database and aligned with the aim to find conserved genusspecific regions suitable for oligonucleotide hybridization. Suitable sequence regions were chosen manually and tested in the online tool OligoAnalyzer 3.1 (Integrated DNA Technologies) for melting temperatures and formation of secondary structures. The specificity of each primer probe set was evaluated in silico in Nucleotide BLAST and considered during the design process, following the guidelines by Rodríguez et al. (2015) [30]. Based on accessible sequences and their reaction properties, six detection systems were designed: Haemonchus (ITS2; system was designed to cover species $H$. contortus and H. placei), Teladorsagia (ITS2; covering T. circumcincta, T. davtiani and T. trifurcata), Trichostrongylus (ITS1; covering T. colubriformis, T. vitrinus and T. rugatus), Nematodirus (SSU rRNA; designed for N. battus), Ashworthius (ITS1; designed for A. sidemi) and Chabertia (COI; designed for Ch. ovina). Duallabeled hydrolysis probes carried a reporter dye (FAM, HEX, TxRd or Cy5) at the 5' end and a compatible black hole quencher (BHQ) at the 3' end. Primers and probes (Table 1) purified by HPLC were purchased from SigmaAldrich. 
Table 1

Primers and probes used in two 4-plex real-time PCR assays.

\begin{tabular}{|c|c|c|c|c|c|}
\hline Target & Target & $\begin{array}{l}\text { Amplicon } \\
\text { size [bp] }\end{array}$ & Fw primer & Rev primer & Probe \\
\hline Haemonchus & ITS2 & 143 & CGTGATGTTATGAAATTGTAAC & CTCAGGTTGCATTATACAAAT & $\begin{array}{l}\text { HEX-TGCCACTATTTGAGTGTACT } \\
\text { BHQ1 }\end{array}$ \\
\hline Teladorsagia & ITS2 & 172 & TACTACAGTGTGGCTAACATA & TTCATTGAGTACATTCAAATAGTAG & $\begin{array}{l}\text { 6FAM- } \\
\text { CCGTCGTAACGTTCCTGAATGAT, }\end{array}$ \\
\hline Trichostrongylus & ITS1 & 116 & GCAATAATACCGCCTCATCG & CATAATGGCGTCTAGGCGAG & $\begin{array}{l}\text { TxRd-TACGGTACCTGGTTCACAG } \\
\text { BHQ2 }\end{array}$ \\
\hline Nematodirus & $\begin{array}{l}\text { SSU } \\
\text { rRNA }\end{array}$ & 150 & CTCTATGGAAGGTGTCTACC & CTAGTCACCAACGTAAAACAG & HEX-CGGCAGTGAATCGTCGTGC, \\
\hline Ashworthius & ITS1 & 167 & TCGATAAATGTGACACAAACTTT & GTACGGGATATAATACTTAGTGAAGTA & $\begin{array}{l}\text { 6FAM- } \\
\text { TGGCGTCATTGAACATGATCATT, } \\
\text { BHQ1 }\end{array}$ \\
\hline Chabertia & $\mathrm{COI}$ & 145 & CACAGGTGTTAAGGTTTTTAG & CAACCTAGAATTTGACAATACTAC & $\begin{array}{l}\text { TxRd- } \\
\text { TTTTTTGTTTACTATTGGTGGTT' } \\
\text { BHQ2 }\end{array}$ \\
\hline IAC & $\begin{array}{l}\text { synthetic } \\
\text { oligo }\end{array}$ & 137 & AACCCCTAAACCGGATGATA & GTTTAGAATGTTTTCTCCCGTAC & Су5-СТСАССТССCCGCCCAATAC \\
\hline
\end{tabular}

Haemonchus (was designed to cover species H. contortus and H. placei), Teladorsagia (covering T. circumcincta, T. davtiani and T.

trifurcata), Trichostrongylus (covering T. colubriformis, T. vitrinus and T. rugatus), Nematodirus (designed for N. battus), Ashworthius (designed for A. sidemi) and Chabertia (designed for Ch. ovina).

The experimental evidence of the unique specificity for each target was validated for each designed detection system by testing homologous and heterologous combinations of the specific set of primers and probes with equimolar amounts of template gDNA (1 ng) extracted from adult nematodes $(H$. contortus, T. circumcincta, T. colubriformis, N. battus, A. sidemi, and Ch. ovina) as well as other closely related species (C. curticei, C. pectinata and $O$. columbianum) commonly parasitizing small ruminants. This evidence was then further verified also in multiplex form by crosswise testing.

Sensitivity was tested in separate reactions for each system at first and further verified in multiplex and on mixed template DNA. Serial 10 -fold dilutions (10 ng - $10 \mathrm{fg}$ per $\mu \mathrm{l}$ ) of stock solutions of gDNA of adult nematodes were used for the tests; similarly, in the case of an experiment with the DNA mixtures, template DNA of three targets was put together (with respect to a certain multiplex assay)

and diluted in the same manner. To determine if a non-competitive environmental DNA could interfere with the assay, $10 \mu \mathrm{g}$ of an excess DNA from fish sperm (SERVA) was added to the samples prior to testing.

Real-time PCR standard curve and internal control. A plasmid DNA construct serving as a positive control in the reaction was prepared based on ITS2 sequence of $H$. contortus. The same amplified sequence as targeted in the relevant multiplex assay by specific primers to $H$. contortus was cloned via Clone Jet (Thermo Fisher Scientific) into vector pJET1.2/blunt and transformed into DH10B competent $E$. coli cells. The plasmid was purified with NucleoBond Xtra kit (Macherey-Nagel), and its DNA concentration determined by NanoDrop. The plasmid construct was sequenced to confirm the proper insertion of intended sequence. The copy number was calculated using the formula: copies $/ \mu \mathrm{l}=\mathrm{X} \mathrm{ng} * 6.022 \times 10^{23} \mathrm{molecules} / \mathrm{mole} /(\mathrm{N} * 660 \mathrm{~g} / \mathrm{mole}) * 1 \times 10^{9} \mathrm{ng} / \mathrm{g} ; \mathrm{where} \mathrm{X}$ is the concentration of the plasmid [ng/ $\mu \mathrm{l}]$ and $\mathrm{N}$ is the length of dsDNA [plasmid with insert]. The calculated copy number was used for preparation of the plasmid stock solution $1 \times 10^{10}$ in $50 \mu \mathrm{g} / \mathrm{ml}$ of carrier DNA from fish sperm and the standard curve was generated by serial dilutions of the plasmid stock to give: $5 \times 10^{7}, 1 \times 10^{7}, 5 \times 10^{6}, 1 \times 10^{6}, 5 \times 10^{5}, 1 \times 10^{5}, 5 \times 10^{4}$, and $1 \times 10^{4}$ copies per $\mu$ l. This series was analysed in duplicate by real-time PCR using Multiplex 1 assay in three replications (three separate plates) to test the efficacy and reproducibility of the reaction. To relate the technical calibration curves of plasmid control to the number of eggs in sheep faeces, we spiked $5 \mathrm{~g}$ of parasite-naïve (trichostrongyle egg-free) sheep faeces with a given number of $H$. contortus eggs. Two independently diluted faecal concentration series ranging from 7,500 to 1 EPG were processed following the DNA extraction for faecal samples described above. We analysed the samples in duplicates and in three replications using Multiplex 1 assay simultaneously with plasmid control.

The sequence of the internal amplification control (IAC) was created by Mikel et al. 2016 [31] from ancient mitochondrial DNA sequences of two extinct species and synthesized de novo (Sigma-Aldrich). This non-competitive synthetic sequence was cloned into a plasmid, purified and diluted using the same protocol as with $H$. contortus plasmid control. Plasmid together with IAC specific primers and hydrolysis probe (Table 1) was incorporated into reaction premix of both multiplex assays to differentiate between truly negative and false negative (inhibited) samples [32].

Real-time PCR reactions and data analysis. All experiments were based on two 4-plex real-time PCR assays using TaqMan technology, whereas Multiplex1 (M1) consisted of detection systems Haemonchus, Teladorsagia and Trichostrongylus, and Multiplex2 (M2) combined detection systems Nematodirus, Ashworthius and Chabertia; detection system for IAC was identical in both multiplex assays. The conditions of multiplex assays were altered systematically until the optimal primer and probe concentrations, concentration of IAC and cycling conditions were determined. The composition of optimized reaction mixture in a final volume of $20 \mu \mathrm{l}$ contained: $1 X$ Luna Universal Probe qPCR Master Mix (New England Biolabs), $250 \mathrm{nM}$ of each of the eight primers, $100 \mathrm{nM}$ of FAM, TxRd and Cy 5 probes and $200 \mathrm{nM}$ of HEX probe, $0.4 \mathrm{U}$ of Antarctic Thermolabile UDG (New England Biolabs), $1 \times 10^{4}$ copies of IAC plasmid and $5 \mu$ l template DNA. All samples were run in duplicates on a CFX96 Touch Real-Time PCR Detection System (Bio-Rad Laboratories) using 96-well PCR plates under 
the following conditions: incubation step at $25^{\circ} \mathrm{C}$ for $10 \mathrm{~min}$ (carryover prevention), initial denaturation at $95^{\circ} \mathrm{C}$ for 2 min followed by 40 cycles of $95{ }^{\circ} \mathrm{C}$ for $15 \mathrm{~s}$ and $57^{\circ} \mathrm{C}$ for $45 \mathrm{~s}$, and a final cooling step of $40^{\circ} \mathrm{C}$ for $30 \mathrm{~s}$.

Plasmid standard, no-template control (NTC) and NICs (in case of real sample analysis) were included on each analysed plate, while IAC was incorporated in every sample, inclusive of controls. The raw data were analysed using the Bio-Rad CFX Manager 3.0 (Bio-Rad Laboratories). The quantification cycle (Cq) values of the samples were read after adjustment of the relative fluorescence units (RFU) threshold line to 140 for FAM, 120 for HEX and 210 for TxRd channel. The sample was considered to be positive only when both replicates provided a positive result and conversely, the sample was considered to be negative only when both replicates gave a negative result, but the IAC gave a positive signal; if this condition was not met, the real-time PCR and/or the DNA extraction was repeated.

\section{Results}

Optimizations. In the specificity tests, no nematode DNAs other than those targeted were amplified and, in all samples, there was a clear signal for the IAC. The only exception was found in the detection system for Nematodirus where $1 \mathrm{ng}$ of T. circumcincta DNA was non-specifically amplified with Cq 34.73 (Table 2). However, this was not observed in the testing of real samples, even though fluorescent signal for Teladorsagia has been reported frequently.

Table 2

Specificity of multiplex assays evaluated with gDNA of adult nematodes.

\begin{tabular}{|c|c|c|c|c|c|c|}
\hline \multirow[t]{3}{*}{ DNA template } & \multicolumn{6}{|c|}{ Detection system } \\
\hline & \multicolumn{3}{|l|}{ Multiplex1 } & \multicolumn{3}{|l|}{ Multiplex2 } \\
\hline & Haemonchus & Teladorsagia & Trichostrongylus & Nematodirus & Ashworthius & Chabertia \\
\hline H. contortus & 23.51 & nd & nd & nd & nd & nd \\
\hline T. circumcincta & nd & 25.54 & nd & $34.73^{*}$ & nd & nd \\
\hline T. colubriformis & nd & nd & 24.05 & nd & nd & nd \\
\hline N. battus & nd & nd & nd & 26.23 & nd & nd \\
\hline A. sidemi & nd & nd & nd & nd & 27.07 & nd \\
\hline Ch. ovina & nd & nd & nd & nd & nd & 25.18 \\
\hline C. curticei & nd & nd & nd & nd & nd & nd \\
\hline C. pectinata & nd & nd & nd & nd & nd & nd \\
\hline O. columbianum & nd & nd & nd & nd & nd & nd \\
\hline
\end{tabular}

Detection systems were designed for Haemonchus (H. contortus, H. placei), Teladorsagia (T. circumcincta, T. davtiani and T. trifurcata), Trichostrongylus (T. colubriformis, T. vitrinus and T. rugatus), Nematodirus (N. battus), Ashworthius (A. sidemi) and Chabertia (Ch. ovina). ${ }^{*}$ Cq value that corresponds to nonspecific amplification. Abbreviation: nd, no DNA was amplified.

The limit of detection (LOD) was the same or better when the mixed samples were run in multiplex mode than when single template DNA was run in either in singleplex and multiplex (data not shown). The LOD of detection systems in multiplex assays was determined to be at least $500 \mathrm{fg}$ of target DNA with the exception of the Ashworthius system, where the LOD was $5 \mathrm{pg}$ (Table 3). An addition of non-competitive excess DNA from fish sperm had no impact on assay performance (data not shown).

Table 3

Evaluation of sensitivity and limit of detection of detection systems in multiplex assays.

\begin{tabular}{|c|c|c|c|c|c|c|}
\hline \multirow[t]{3}{*}{ Mixed template DNA } & \multicolumn{6}{|c|}{ Detection system } \\
\hline & \multicolumn{3}{|l|}{ Multiplex1 } & \multicolumn{3}{|l|}{ Multiplex2 } \\
\hline & Haemonchus & Teladorsagia & Trichostrongylus & Nematodirus & Ashworthius & Chabertia \\
\hline $50 \mathrm{ng}$ & 16.54 & 17.29 & 17.54 & 18.79 & 18.82 & 16.23 \\
\hline $5 \mathrm{ng}$ & 19.82 & 20.50 & 21.05 & 22.34 & 22.26 & 19.80 \\
\hline $500 \mathrm{pg}$ & 23.70 & 24.32 & 24.67 & 26.31 & 25.86 & 23.42 \\
\hline $50 \mathrm{pg}$ & 27.35 & 27.96 & 28.16 & 30.01 & 29.48 & 26.91 \\
\hline $5 \mathrm{pg}$ & 31.10 & 32.18 & 31.60 & 34.06 & 34.61 & 30.11 \\
\hline $500 \mathrm{fg}$ & 34.74 & 35.90 & 35.23 & 38.41 & nd & 33.54 \\
\hline $50 \mathrm{fg}$ & nd & nd & nd & nd & nd & nd \\
\hline
\end{tabular}

The sensitivity was assessed with equimolarly mixed gDNAs of adult nematodes (in particular, DNA template for Multiplex 1 consisted of $H$. contortus, $T$. circumcincta and T. colubriformis; Multiplex2 of N. battus, A. sidemi and Ch. ovina). Abbreviation: nd, no DNA was detected. 
Efficacy and reproducibility. Based on the median values of $H$. contortus ITS2 plasmid standard calibration curve (Figure 1), the PCR efficiency was established to be $99.63 \%$, correlation coefficient 0.9997 , slope -3.3308 and $y$ intercept 40.074 . The standard deviation (SD) of the Cq values within the plasmid DNA replicates between plates was $<0.11$ and the coefficient of variation $(\mathrm{CV})<0.76 \%$ (Table 4$)$.

Table 4

Repeatability and reproducibility of multiplex real-time PCR reactions.

\begin{tabular}{|c|c|c|}
\hline $\begin{array}{l}\text { Plasmid copies } \\
\text { per } \mu \mathrm{l}\end{array}$ & $\begin{array}{l}\text { Median } \\
\pm \text { SD }\end{array}$ & $\begin{array}{l}\text { CV } \\
(\%)\end{array}$ \\
\hline $5 \times 10^{7}$ & $\begin{array}{l}14.49 \pm \\
0.11\end{array}$ & 0.76 \\
\hline $1 \times 10^{7}$ & $\begin{array}{l}16.74 \pm \\
0.04\end{array}$ & 0.22 \\
\hline $5 \times 10^{6}$ & $\begin{array}{l}17.78 \pm \\
0.05\end{array}$ & 0.30 \\
\hline $1 \times 10^{6}$ & $\begin{array}{l}20.02 \pm \\
0.10\end{array}$ & 0.52 \\
\hline $5 \times 10^{5}$ & $\begin{array}{l}21.12 \pm \\
0.05\end{array}$ & 0.22 \\
\hline $1 \times 10^{5}$ & $\begin{array}{l}23.30 \pm \\
0.10\end{array}$ & 0.44 \\
\hline $5 \times 10^{4}$ & $\begin{array}{l}24.44 \pm \\
0.06\end{array}$ & 0.25 \\
\hline $1 \times 10^{4}$ & $\begin{array}{l}26.84 \pm \\
0.08\end{array}$ & 0.31 \\
\hline
\end{tabular}

Median \pm standard deviation (SD) and coefficient of variation (CV) of Cq values of three repetitions of $H$. contortus ITS2 plasmid standard.

Semi-quantitative data evaluation. Based on median values of faecal series calibration curve (Figure 2A) the PCR efficiency was established to be $83.37 \%$, correlation coefficient 0.9869 , slope -3.7974 and $y$ intercept 32.181 . The SD of the replicates between plates was $<0.59$ and CV $<2.11 \%$.

The Cq values of faecal concentration series ranging from 7,500 to 1 EPG were correlated to the corresponding values of $H$. contortus ITS2 plasmid standard copies enabling a semi-quantitative estimation (Figure 2B) of the number of eggs in unknown samples.

Since not all GIN detection systems are using the same target marker gene, "correction factors" were calculated to overcome their different representation in the respective genome (an issue for all ITS sequences [13]). Equimolar mixed gDNAs of adult nematodes were tested repeatedly, identifying slight biases in performance between the different molecular targets. Since these biases, obtained by comparing Cq values of samples of the same DNA concentration were similar for individual targets in different nematode isolates, replicates and plate replications, the correction factors were established as follows, taking H. contortus as the reference value (1): T. circumcincta (0.893; $95 \%$ confidence interval (Cl): $0.853-0.934)$, T. colubriformis (0.966; $95 \% \mathrm{Cl}: 0.943-0.989), N$. battus (0.910; 95\% Cl: 0.889-0.930), A. sidemi (0.879; 95\% Cl: 0.861-0.897) and Ch. ovina (0.995; 95\% Cl: 0.967-1.022).

To enable evaluation, the $\mathrm{Cq}$ value of each detected target sequence in the analysed sample was firstly assigned to plasmid copy number counting with the calibration curve of plasmid control on the plate, sample dilution and respective correction factor. Plasmid copy number was then used to estimate the EPG value of the target, based on the formula for semi-quantitative evaluation (Figure 2B). EPG values of individual targets of the sample were summed to obtain the estimation of overall infection intensity (total EPG), whereas the limit values for interpretation were set to < 100 EPG in low infection, $100-1000$ EPG medium infection and > 1000 EPG high infection; the same cut-off values were used for evaluation of faecal egg counts (FEC) results.

It was found that $1 \mathrm{EPG}$ corresponds to 234 copies of plasmid standard, which was considered a minimum limit for a positive detection in the faecal samples.

Functional verification of the multiplex assays. In this study, a total of 44 individual faecal samples from three sheep farms in the Czech Republic were examined using the faecal flotation technique and tested by two 4-plex real-time PCR assays to verify the functionality of the designed assays and to evaluate the validity of proposed semi-quantitative evaluation. Strongylid-type eggs were detected by the Concentration McMaster technique in 40 (91\%) out of the 44 faecal samples collected on three sheep farms (Table 5); except from Nematodirus spp. which was found/identified in only six samples (14\%). In contrast, strongylid DNA was detected by the multiplex real-time PCR in 43 (97.7\%) samples (Table 5); the highest percentages of test-positive samples were related to Haemonchus (89\%), followed by Teladorsagia (82\%), Chabertia (73\%) and, to a lesser extent, Trichostrongylus (61\%), whereas both N. battus and A. sidemi DNA was absent.

In addition, total EPG calculated from Cq value and the relative proportions of the different nematodes in each sample were compared with the FEC from the faecal samples of the same individuals determined by the Concentration McMaster technique (Table 6). There was fair agreement in the evaluation of the infection severity between results obtained by these two techniques/methods when based on total EPG (weighted kappa $0.315 \pm 0.107$ ) and moderate agreement when based on the results of the most pathogenic genus, Haemonchus (weighted kappa $0.478 \pm 0.109$ ). Only one sample (No. 21) tested negative for all screened targets by both techniques, although having positive IAC indicated that faecal inhibitors were not responsible for the negative results in multiplex real-time PCR. Three samples (No. 25, 31 and 34) tested negative by coprological examination but positive in multiplex assay, whereas samples No. 31 and 34 were evaluated as severe infections. Mixed infections were observed in $100 \%$ of positively tested samples with at least two trichostrongyle representants detected. 
Table 5

Functional verification of the multiplex assays based on analysis of 44 faecal samples.

\begin{tabular}{|c|c|c|c|c|c|c|c|c|c|}
\hline \multirow[t]{2}{*}{$\begin{array}{l}\text { Total no. of } \\
\text { samples tested }\end{array}$} & \multicolumn{3}{|c|}{$\begin{array}{l}\text { No. of samples test-positive by the faecal } \\
\text { flotation technique }\end{array}$} & \multicolumn{6}{|c|}{ Number of samples test-positive by multiplex real-time PCR } \\
\hline & Total & $\begin{array}{l}\text { Strongylid- } \\
\text { type eggs }\end{array}$ & $\begin{array}{l}\text { Nematodirus } \\
\text { spp. }\end{array}$ & Total & Haemonchus & Teladorsagia & Trichostrongylus & Chabertia & $\begin{array}{l}\text { Mixed } \\
\text { infections }\end{array}$ \\
\hline $44(100 \%)$ & $\begin{array}{l}40 \\
(90.9 \%)\end{array}$ & $\begin{array}{l}40 \\
(90.9 \%)\end{array}$ & $\begin{array}{l}6^{\star} \\
(13.6 \%)\end{array}$ & $\begin{array}{l}43 \\
(97.7 \%)\end{array}$ & $\begin{array}{l}39 \\
(88.6 \%)\end{array}$ & $\begin{array}{l}36 \\
(81.8 \%)\end{array}$ & $\begin{array}{l}27 \\
(61.4 \%)\end{array}$ & $\begin{array}{l}32 \\
(72.7 \%)\end{array}$ & $\begin{array}{l}43 / 44 \\
(97.7 \%)\end{array}$ \\
\hline
\end{tabular}

Each sample was subjected to quantitative coprological examination using the Concentration McMaster technique for enumeration of strongylid-type eggs and eggs of Nematodirus spp. (includes all species except $N$. battus; ${ }^{*} N$. battus was described in one sample).After DNA extraction, multiplex realtime PCR analysis was performed, targeting within two assays Haemonchus (H. contortus, H. placel), Teladorsagia (T. circumcincta, T. davtiani and T. trifurcata), Trichostrongylus (T. colubriformis, T. vitrinus and T. rugatus), and Chabertia (Ch. ovina). Nematodirus (N. battus) and Ashworthius (A. sidemi) DNA was not detected. 
Table 6

Evaluation of infection intensity in 44 faecal samples from three farms.

\begin{tabular}{|c|c|c|c|c|c|c|c|c|c|}
\hline \multicolumn{2}{|c|}{ Sample } & \multirow{2}{*}{\multicolumn{2}{|c|}{$\begin{array}{l}\text { Coprological diagnoses } \\
\text { Strongylide-type eggs }\end{array}$}} & \multicolumn{6}{|c|}{ Molecular diagnoses } \\
\hline \multirow[b]{2}{*}{ No. } & \multirow[b]{2}{*}{ ID } & & & \multicolumn{6}{|c|}{ Semi-quantitative estimation of the number of eggs } \\
\hline & & FEC & $\begin{array}{l}\text { Degree of } \\
\text { infection }\end{array}$ & $\begin{array}{l}\text { Total } \\
\text { EPG }\end{array}$ & $\begin{array}{l}\text { Degree of } \\
\text { infection }\end{array}$ & Haemonchus & Teladorsagia & Trichostrongylus & Chabertia \\
\hline 1 & $\mathrm{~F} 1$ & 1720 & high & 5596 & high & 3731 & 1623 & 0 & 242 \\
\hline 2 & $\mathrm{~F} 1$ & 1220 & high & 1348 & high & 1121 & 189 & 0 & 38 \\
\hline 3 & $\mathrm{~F} 1$ & 7160 & high & 10477 & high & 8648 & 1751 & 0 & 78 \\
\hline 4 & $\mathrm{~F} 1$ & 1520 & high & 2425 & high & 1960 & 137 & 0 & 328 \\
\hline 5 & $\mathrm{~F} 1$ & 260 & medium & 657 & medium & 201 & 93 & 0 & 363 \\
\hline 6 & $\mathrm{~F} 1$ & 800 & medium & 1125 & high & 958 & 66 & 0 & 101 \\
\hline 7 & $\mathrm{~F} 1$ & 720 & medium & 4674 & high & 4544 & 23 & 0 & 107 \\
\hline 8 & $\mathrm{~F} 1$ & $460(+20$, N. battus $)$ & medium & 912 & medium & 911 & 1 & 0 & 0 \\
\hline 9 & F1 & 2000 & high & 7187 & high & 6212 & 877 & 0 & 98 \\
\hline 10 & $\mathrm{~F} 1$ & 700 & medium & 1308 & high & 533 & 451 & 0 & 324 \\
\hline 11 & $\mathrm{~F} 1$ & 400 & medium & 713 & medium & 551 & 94 & 0 & 68 \\
\hline 12 & $\mathrm{~F} 1$ & 2220 & high & 6376 & high & 5569 & 717 & 0 & 90 \\
\hline 13 & F1 & 2000 & high & 6903 & high & 5637 & 962 & 0 & 304 \\
\hline 14 & F2 & 240 & medium & 651 & medium & 67 & 543 & 1 & 40 \\
\hline 15 & $\mathrm{~F} 2$ & 240 & medium & 2735 & high & 2545 & 0 & 138 & 52 \\
\hline 16 & $\mathrm{~F} 2$ & 240 & medium & 1112 & high & 1036 & 0 & 20 & 56 \\
\hline 17 & $\mathrm{~F} 2$ & 2640 & high & 11005 & high & 7274 & 2922 & 809 & 0 \\
\hline 18 & F2 & 2020 & high & 902 & medium & 853 & 17 & 32 & 0 \\
\hline 19 & $\mathrm{~F} 2$ & 140 & medium & 634 & medium & 163 & 425 & 44 & 2 \\
\hline 20 & $\mathrm{~F} 2$ & 1020 & high & 2062 & high & 1313 & 581 & 24 & 144 \\
\hline 21 & F2 & 0 & - & 0 & - & 0 & 0 & 0 & 0 \\
\hline 22 & $\mathrm{~F} 2$ & 40 & low & 628 & medium & 231 & 397 & 0 & 0 \\
\hline 23 & F2 & 400 & medium & 2571 & high & 403 & 1765 & 116 & 287 \\
\hline 24 & $\mathrm{~F} 2$ & 480 & medium & 1224 & high & 359 & 759 & 79 & 27 \\
\hline 25 & F3 & 0 & - & 42 & low & 39 & 0 & 3 & 0 \\
\hline 26 & F3 & 40 & low & 171 & medium & 2 & 168 & 0 & 1 \\
\hline 27 & F3 & 40 & low & 2372 & high & 4 & 2271 & 66 & 31 \\
\hline 28 & F3 & 80 & low & 1079 & high & 134 & 939 & 6 & 0 \\
\hline 29 & F3 & 20 & low & 178 & medium & 160 & 0 & 15 & 3 \\
\hline 30 & F3 & 3020 & high & 8126 & high & 160 & 5776 & 2188 & 2 \\
\hline 31 & F3 & 0 & - & 19676 & high & 14140 & 1005 & 4522 & 9 \\
\hline 32 & F3 & $\begin{array}{l}860(+80, \text { Nematodirus } \\
\text { spp.) }\end{array}$ & medium & 5207 & high & 930 & 1818 & 2410 & 49 \\
\hline 33 & F3 & 20 & low & 41 & low & 0 & 0 & 15 & 26 \\
\hline 34 & F3 & 0 & - & 1001 & high & 71 & 179 & 751 & 0 \\
\hline 35 & F3 & 80 & low & 249 & medium & 245 & 0 & 4 & 0 \\
\hline 36 & F3 & 40 & low & 489 & medium & 0 & 471 & 0 & 18 \\
\hline 37 & F3 & 780 & medium & 622 & medium & 0 & 229 & 387 & 6 \\
\hline 38 & F3 & 100 & medium & 15301 & high & 9564 & 2984 & 2733 & 20 \\
\hline
\end{tabular}




\begin{tabular}{|c|c|c|c|c|c|c|c|c|c|}
\hline \multirow{2}{*}{\multicolumn{2}{|c|}{ Sample }} & \multirow{2}{*}{\multicolumn{2}{|c|}{$\begin{array}{l}\text { Coprological diagnoses } \\
\text { Strongylide-type eggs }\end{array}$}} & \multicolumn{6}{|c|}{ Molecular diagnoses } \\
\hline & & & & \multicolumn{6}{|c|}{ Semi-quantitative estimation of the number of eggs } \\
\hline 39 & F3 & 5940 & high & 382 & medium & 69 & 201 & 112 & 0 \\
\hline 40 & F3 & 13640 & high & 15287 & high & 12564 & 190 & 2533 & 0 \\
\hline 41 & F3 & $\begin{array}{l}1200(+40, \text { Nematodirus } \\
\text { spp.) }\end{array}$ & high & 27479 & high & 22256 & 2327 & 2797 & 99 \\
\hline 42 & F3 & $\begin{array}{l}5780(+120, \text { Nematodirus } \\
\text { spp.) }\end{array}$ & high & 3788 & high & 0 & 2806 & 982 & 0 \\
\hline 43 & F3 & $\begin{array}{l}7780(+120, \text { Nematodirus } \\
\text { spp.) }\end{array}$ & high & 109 & medium & 39 & 0 & 6 & 64 \\
\hline 44 & F3 & $\begin{array}{l}12080 \text { (+ 100, } \\
\text { Nematodirus spp.) }\end{array}$ & high & 12646 & high & 5855 & 3355 & 3425 & 11 \\
\hline
\end{tabular}

Total EPG calculated from Cq values resulting from multiplex real-tiime PCR and the relative proportions of the different nematodes in each sample were compared with the FEC from the faecal samples of the same individuals determined by the Concentration McMaster technique (sensitivity of 20 EPG). For multiplex real-time PCR the amount of 1 EPG corresponding to 234 copies of plasmid standard was considered a minimum limit for positive detection. Nematodirus (N. battus) and Ashworthius (A. sidemi) DNA was absent.

To further compare coproscopy to molecular approach, LC prepared from the pooled flock samples were included. GIN composition on farms based on morphological identification of $\mathrm{L}_{3}$ was evaluated as follows: at Farm 1 (F1) were differentiated in $73 \%$ as Haemonchus, 10\% Teladorsagia, 8\%

Trichostrongylus, and 9\% Chabertia; Farm 2 (F2) was in 41\% Haemonchus, 22\% Teladorsagia, 17\% Trichostrongylus, and 20\% Chabertia; and finally at Farm 3 (F3) was identified in 48\% Haemonchus, $18 \%$ Teladorsagia, and $34 \%$ Trichostrongylus.

\section{Discussion}

PGE in ruminants is usually caused by a mixture of GINs occurring simultaneously [3,33]. Therefore, the potential implications for studying these parasites (population biology, epidemiology, treatment efficacy etc.) offered by quantitative and multiplex PCR assays seem highly valuable. The advantages are manifold and besides simultaneous detection of multiple parasites present in a sample (use of three different dyes for the six targets means that only one third of the number of reactions must be performed to diagnose all six GINs) include high-throughput capacity, wide dynamic range and avoidance of inaccuracies related to end-point analysis. High-throughput sequencing devices are being increasingly applied to the challenge of GIN identification [34] and complex nematode community studies [35, 36,37]. This 'nemabiome'-type technology is still relatively expensive and requires expertise and complicated bioinformatic analysis, so is still the preserve of specialist laboratories. In contrast, real-time PCR technology is very widespread today and became common equipment of larger laboratories, allowing diagnostic procedures based on these platforms to be used relatively routinely. This fact, together with time and laboratory simplicity ensuring immediate results without bioinformatic pipelines, bringing our present multiplex real-time PCR assays for specific detection and semi-quantitative evaluation of the most prevalent GIN infections directly from faeces of domestic livestock closer to the wider scientific community.

Roeber et al. (2012) [17] developed an automated multiplexed-tandem PCR (MT-PCR), with properties very similar to our approach, with the possible exception that the individual species real-time components are carried out in parallel, in separate reactions, rather than simultaneously in the same reaction. The platform, targeting ITS2 regions of six GINs (Haemonchus spp., T. circumcincta, Trichostrongy/us spp., Oesophagostomum spp., Ch. ovina, and C. curticel) was validated for European applications[22] and showed promise for routine use in practice. Although they tested direct extraction of DNA out of $0.25 \mathrm{~g}$ of faeces using the PowerSoil DNA purification kit (MoBio) as one of the possible methods in the MTPCR study [17], the results showed decreased detection sensitivity which led to decision of the continued use of previously extracted eggs $/ \mathrm{L}_{3}$ larvae only. In comparison, we see the advantage of our approach in need for no additional equipment such as handling robot devices and in the usage of faecal samples directly to DNA extraction. The utilization of preextraction steps focused on proper homogenization and sample dissolution, and the usage of specialized kit possessing inhibitor removal technology improved the extraction process and overcame this issue in the case of our study. These provisions ensured a higher sample input, increased diagnostic sensitivity, and reduced the overall time. This was demonstrated by detecting samples' false negative by FEC (possibly in a prepatent stage of infection) and by the absence of PCR inhibition evidenced by IAC amplification.

The parasites for which the multiplex real-time PCR assays are described in this study represent, apart from A. sidemi, the most important GIN of sheep. The oligonucleotides designed for this study show sequence identity with the currently available NCBI GenBank database gene sequences of individual targets (data not shown). Therefore, even though we did not investigate the specific detection of further targeted species of the same genera (namely $H$. placei, $T$. davtiani, T. trifurcata, T. vitrinus, and T. rugatus) due to the unavailability of DNA material, it can be assumed that the respective probes will detect even these closely related species for which the present detection systems were intended [14].

Ashworthius detection was included in the presented multiplex assay for the following reasons. This hematophagous abomasal nematode is phylogenetically related and morphologically/morphometrically almost indistinguishable in immature stages from $\mathrm{H}$. contortus, and poses a threat to become one of the most widespread pathogenic GINs of autochthonous European ruminants [29]. This invasive parasite originally endemic in Asiatic deer was probably introduced to Europe by sika deer in the late 19th and early 20th century and since then it has successfully spread among new hosts (such as red deer, roe deer, fallow deer, or moose) and is highly pathogenic in some e.g. European bison [38]. The susceptibility of domestic sheep to ashworthiosis has so far only been confirmed experimentally [39], whereas the first cases of natural infection in cattle were recorded in Poland by Moskwa et al. (2015) [40]. Thus, horizontal transmission 
of this parasite from wild ruminants to domestic livestock is probably just a matter of time in all regions where these hosts share the same pastures. Thus, having access to a reliable diagnostic tool that can detect $A$. sidemi in livestock was the main purpose of including this parasite in our multiplex assay.

Detection systems for members in the genus Nematodirus are typically not included in similar studies devoted to strongyle nematodes of livestock due to their distinguishability based on the eggs, which are much larger and contain distinctive dark cells. However, N. battus is an especially important pathogen in temperate climates causing significant health problems in grazing lambs in spring. For this reason, we decided to include this species in the multiplex assay aimed at faecal samples, which could be used as an alternative tool to coproscopy. During the assay's specificity tests, we noticed a weaker non-specific amplification of T. circumcincta DNA (Table 2) with the Nematodirus system. However, this phenomenon was not recorded during tests on faecal samples, even in those with a high EPG in the Teladorsagia system (Table 6). This anomaly could be caused either by the presence of other Teladorsagia species than $T$. circumcincta, to which the $N$. battus probe did not bind, due to sequence variations or it was more likely due to the presence of an excess amount of nonspecific DNAs in a complex sample, such as faeces, that might block nonspecific hybridization during the PCR reaction the same way as sheared DNAs [32, 41, 42]; such enhancement of specificity has previously been demonstrated by the usage of competing primers [43] or presence of tRNA [44]. In the present study, Nematodirus spp. was detected only in six faecal samples out of 44 examined by McMaster (Table 5). In five of these samples (No. 32, 41-44) the Nematodirus spp. eggs were identified, while in one (No. 8) N. battus was also present but only judged on a single egg. Sample No. 8 was re-extracted and tested repeatedly by multiplex real-time PCR but always with negative results. This could be as a result either of the misidentification of Nematodirus species based on a single egg (since other species than $N$. battus would not be detected by our assay, e.g., $N$. filicollis, $N$. helvetianus), sampling error (no eggs were present in the faecal sample used for molecular analysis), or because the amount of DNA was below the LOD for this system. The use and suitability of this detection system needs to be further evaluated during a broader study on field samples from sheep flocks.

The LOD determined by assays sensitivity tests on adult nematodes gDNAs (Table 3) cover the range of 0.5-5 pg which equates to a proportion of gDNA extracted from a single egg [11]. These results are consistent with previous studies based on other singleplex [11, 21] and multiplex real-time PCR assays [25]. To refine the data interpretation for faecal samples, the limit of 1 EPG corresponding to 234 plasmid copies was established. In the present study, this corresponded to Cq 35.51 in Haemonchus, Cq 39.75 in Teladorsagia, Cq 36.77 in Trichostrongylus, Cq 39.03 in Nematodirus, Cq 40.00 in Ashworthius, and Cq 35.70 in Chabertia detection system, which all were derived from the median values of a plasmid standard.

Based on IAC, which was amplified in all samples, there was no evidence of inhibition in the PCR following the column extraction of gDNA directly from faeces. Due to recent improvements in commercial faecal extraction kits towards purification of the sample suitable for downstream molecular-based applications, faecal inhibitors themself are no longer of the biggest concern today. Harmon et al. (2007) [18] pointed out that the factor causing the majority of the variance in Cq values between samples containing the same numbers of eggs is partly attributed to the procedure of DNA extraction, when the variation seen from amplified egg DNA exceeded that obtained with plasmids. They also suggested that these variances are corrected in multiplex reactions where intra-sample comparisons are made for each trichostrongyle target [18]. Similarly to Avramenko et al. (2015) [36], we calculated genus specific correction factors to eliminate any sequence representation bias (which could be given for example by the different target sequence features or their copy number in respective genomes). Still, the limit values $0.879-1.0$ of their range points to the minimal effect of these parameters on resulting values.

Bott et al. (2009) [11] used a microscopic McMaster approach combined with molecular real-time PCR followed by melting-curve analysis optimized for extracted eggs and suggested that such a platform can be used for the semi-quantitation of target DNAs and infection intensity evaluation based on Cq values of individual targets. The reason for this consideration was that semi-quantitative evaluation together with knowledge of species/genus composition is more valuable than absolute quantification, given that the intensity of nematode infection does not have to reflect the number of eggs excreted per gram of faeces; the exception to this are nematodes with a high biotic potential (e.g., H. contortus and Oesophagostominae) [11]. Based on this knowledge and experience, we conclude that a semi-quantitative enumeration of different GIN eggs in faeces based just on ITS2 H. contortus plasmid control is feasible by our multiplex real-time PCR assays. The results of individual faecal samples (Table 6) and their comparison to FEC suggests with the moderate agreement in the evaluation of the infection severity, that genus Haemonchus is confirmed as the most pathogenic GIN in sheep [45], being widespread and highly prolific, the trigger point for diagnostic evaluation and the selection of follow-up measures, at least under European conditions. Knowledge of the representation of other species in the sample adds further diagnostic value and may influence the choice of subsequent control and treatment procedures; these may then differ from those determined just on the basis of FEC results. Testing of the 44 individual faecal samples revealed three samples, where the presence of nematodes remained undetected by the coproscopy, but this negativity turned out to be false by multiplex real-time PCR. However, this was not noted the other way around, i.e., there were no samples positive in FEC which would test negative by molecular analysis. This indicates that the molecular approach is more sensitive for the detection of eggs directly from faeces than the Concentration McMaster technique, where one egg equates to 20 EPG. These observations are basically in agreement with earlier results by Sweeny et al. (2011) [16]. Nematode composition based on LC proportionally agreed with those resulting from multiplex assays, however, a slight bias can be observed in the example of F1, where Trichostrongylus DNA was not detected but microscopically determined at $8 \%$ according to LC results. Since Teladorsagia was the second most abundant genus on this farm, this indicates a confusion of Trichostrongylus and Teladorsagia larvae during microscopical identification of $L_{3}$. Usually these two genera are grouped together even with an experienced observer [27]. The high sensitivity of the present multiplex realtime PCR, together with the approach of individual animal testing, preventing bias of the result due to animals with aggregated parasites, are the required features for reliable GIN diagnostics.

Although, emphasis must be placed on proper homogenization and mechanical cell disruption of the faeces, there are several advantages of using multiplex real-time PCR assays compared to LC. The most noticeable advantage is the significant shortening in number of steps included in the procedure resulting in reduction of the whole procedure duration from 7 days on cultured $L_{3}$ [46], 2 days with $L_{1}$ [14], to only a few hours in the case of the present multiplex assays. Detection of specific DNA also allows GIN diagnostics on frozen faecal samples, where the vast majority of eggs rupture or are otherwise damaged causing gDNA release. 
Another indisputable but little known and underestimated advantage of using biological samples directly is the presence of parasite cell-free DNA (cfDNA). CfDNA is released during disintegration of different life stages (cellular apoptosis/necrosis) and active secretion from cells and its presence (and other parasite components) within the faeces cannot be identified by microscopy [47]. The detection of cfDNA is being increasingly applied as an efficient biomarker for the accurate diagnosis of parasites occupying tissues and the circulatory system. The presence of extracellular cfDNA helps to overcome problems connected with intermittent egg shedding and thus greatly increases the sensitivity and accuracy of the semi-quantitative diagnostic assay. Its presence can also reveal the prepatent stage or the hypobiotic larvae (arrested larval development) [11], since cfDNA is released by the larvae present in the wall of the gastrointestinal tract. The theory of cfDNA and its potential to increase assay accuracy might be supported by individual faecal sample results that tested negative by microscopical FEC; in the case of sample No. 25, we assume that a low intensity of infection detected by multiplex assay (total EPG $=44$ ) could adversely affect faecal flotation, which may be subject to a dilution error, but this was presumably not the case in the other two samples. Samples No. 31 and 34 tested negative by faecal flotation technique but highly positive by multiplex real-time PCR [25], with rankings of severe infections. In both samples, high levels of Haemonchus, Teladorsagia and Trichostrongylus were detected. A possible explanation for these results could be a prepatent period of infection with a high representation of developing larval stages. Although less likely scenarios such as some form of hypobiosis or sampling error given, e.g., by intermittent egg shedding, cannot be ruled out; the faeces for both tests were collected at the same time of the day, and we reckon that in such a heavy infection would be at least some eggs present anyway.

No molecular approach for specific DNA detection of GINs in sheep using fresh faeces has yet been implemented in standard diagnosis practice. In our opinion, the two multiplex real-time PCR assays presented in this study may allow reliable evaluation of GIN genus/species richness within European sheep flocks and thus improve diagnosis of GIN infections in ruminant livestock. Presented preliminary evidence of the assays' ability to rapidly identify and rank nematodes according to their numerical contribution to observed FEC in mixed infections may also suggest the potential to become a powerful alternative or practical adjunct to conventional faecal egg count reduction tests (FECRT) to enable the rapid inference of which strongyle species or genera are susceptible or resistant to particular anthelmintic drugs $[12,16]$. However, further evaluation and refinements of these assays needs to be carried out during further testing on real samples to refine its precision; then it could usefully supplement or replace the conventional coprological techniques for the purpose of routine diagnosis.

\section{Conclusions}

Two multiplex real-time PCR assays designed in this study, containing among other things an internal amplification control to avoid false negative results, targeting the main GINs of sheep and were successfully tested for detection of H. contortus, T. circumcincta, T. colubriformis, N. battus, Ch. ovina, and, atypically, A. sidemi as an invasive threat to sheep flocks. These assays were optimized to be performed using DNA extracted directly from faeces and tests of individually collected faecal samples from three farms showed greater sensitivity of molecular screening in comparison to coproscopy. The knowledge of species proportion within the sample, together with semi-quantitative evaluation of FEC for each genus/species adds value to the diagnostic readout and, in our opinion, has the potential to improve current diagnostic approaches. The assays will allow the performance of extensive epidemiological/demographics studies on the major gastrointestinal parasites of sheep and also add a high degree of precision to anthelmintic efficacy testing protocols.

\section{Declarations}

\section{Ethics approval and consent to participate}

The farmers gave permission to collect faecal samples from animals and provided gastrointestinal tract of sheep slaughtered for human consumption. The research was approved by the Institutional ethics and animal welfare committee of the Czech University of Life Sciences Prague. Handling of animals, collection of faecal samples as well as parasitological dissection of sheep gastrointestinal tract were in line with the national legislation of the Czech Republic - Act on the protection of animals against cruelty, Act No 246/1992 Coll. The experimental infection of sheep with Haemonchus contortus was approved by both the Institutional ethics and animal welfare committee of the Czech University of Life Sciences Prague and The Ministry of Education, Youth and Sports of the Czech Republic (MSMT-5920/2017-2).

\section{Consent for publication}

Not applicable.

\section{Availability of data and materials}

All data generated or analysed during this study are included in this published article. The datasets used and/or analysed during the current study are available from the corresponding author on reasonable request.

\section{Competing interests}

The authors declare that they have no competing interests.

\section{Funding}


The work was financially supported by an INTER COST project by the Czech Republic Ministry of Education, Youth and Sports (LTC19018). This article is based upon work from the COST Action COMBAR CA16230, supported by COST (European Cooperation in Science and Technology) which facilitated collaboration for this work. The funder had no role in study design, data collection and analysis, interpretation of data or drafting the manuscript.

\section{Authors' contributions}

N.R. designed the study, designed the detection systems, optimized the multiplex assays, performed molecular work, analysed data, and wrote the manuscript. L.S. contributed to the molecular work, designed the evaluation system, and consulted on experimental work. I.A.K. performed coprological examinations and larval cultures. J.V. performed morphometric measurements, secured the biological material, and revised the manuscript. J.H. and P.S. consulted on data interpretation and revised the manuscript. M.K. provided financial support, consulted on data interpretation, and revised the manuscript. All authors contributed to the final version of the manuscript.

\section{Acknowledgements}

The authors are grateful to the sheep farmers for providing samples for this study. This research was performed within the Centre for Infectious Animal Diseases (CINeZ) initiative; experimental animal care was provided with the assistance of the staff of the Demonstration and Experimental Center, Faculty of Agrobiology, Food and Natural Resources, Czech University of Life Sciences Prague.

\section{References}

1. Scott I, Sutherland I. Gastrointestinal Nematodes of Sheep and Cattle: Biology and Control. Wiley-Blackwell; 2009. p. 256.

2. Zajac AM. Gastrointestinal nematodes of small ruminants: Life cycle, anthelmintics, and diagnosis. Veterinary Clinics of North America-Food Animal Practice. 2006;22 3: 529-541; doi: 10.1016/j.cvfa.2006.07.006.

3. Herd RP. Epidemiology and Control of Nematodes and Cestodes in Small Ruminants - Northern United-States. Veterinary Clinics of North America-Food Animal Practice. 1986;2 2:355-62. doi:10.1016/s0749-0720(15)31245-7.

4. Kyrianova IA, Kopecky O, Slosarkova S, Vadlejch J. Comparison of internal parasitic fauna in dairy goats at conventional and organic farms in the Czech Republic. Small Ruminant Research. 2019;175:126-32. doi:10.1016/j.smallrumres.2019.05.003.

5. Hoste H, Torres-Acosta JFJ. Non chemical control of helminths in ruminants: Adapting solutions for changing worms in a changing world. Vet Parasitol. 2011;180 1-2:144 - 54; doi: 10.1016/j.vetpar.2011.05.035.

6. Kaplan RM. Drug resistance in nematodes of veterinary importance: a status report. Trends in Parasitology. 2004;20 10:477-81. doi:10.1016/j.pt.2004.08.001.

7. Wolstenholme AJ, Fairweather I, Prichard R, von Samson-Himmelstjerna G, Sangster NC. Drug resistance in veterinary helminths. Trends in Parasitology. 2004;20 10:469-76. doi:10.1016/j.pt.2004.07.010.

8. Roeber F, Jex AR, Gasser RB. Real-Time A. PCR Assay for the Diagnosis of Gastrointestinal Nematode Infections of Small Ruminants. Veterinary Infection Biology: Molecular Diagnostics and High-Throughput Strategies. 2015;1247:145-52; doi: 10.1007/978-1-4939-2004-4_10.

9. Vercruysse J, Charlier J, Van Dijk J, Morgan ER, Geary T, von Samson-Himmelstjerna G, et al. Control of helminth ruminant infections by 2030. Parasitology. 2018;145 13:1655-64. doi:10.1017/s003118201700227x.

10. Höglund J, Elmahalawy ST, Halvarsson P, Gustafsson K. Detection of Haemonchus contortus on sheep farms increases using an enhanced sampling protocol combined with PCR based diagnostics. Veterinary Parasitology: X. 2019;2:100018.

11. Bott NJ, Campbell BE, Beveridge I, Chilton NB, Rees D, Hunt PW, et al. A combined microscopic-molecular method for the diagnosis of strongylid infections in sheep. Int J Parasitol. 2009;39 11:1277-87. doi:10.1016/j.ijpara.2009.03.002.

12. Roeber F, Larsen JWA, Anderson N, Campbell AJD, Anderson GA, Gasser RB, et al. A Molecular Diagnostic Tool to Replace Larval Culture in Conventional Faecal Egg Count Reduction Testing in Sheep. Plos One 2012;7 5; doi:10.1371/journal.pone.0037327.

13. Höglund J, Engström A, von Samson-Himmelstjerna G, Demeler J, Tydén E. Real-time PCR detection for quantification of infection levels with Ostertagia ostertagi and Cooperia oncophora in cattle faeces. Vet Parasitol. 2013;197(1-2):251-7. doi:10.1016/j.vetpar.2013.04.044.

14. von Samson-Himmestjerna G, Harder A, Schnieder T. Quantitative analysis of ITS2 sequences in trichostrongyle parasites. Int J Parasitol. 2002;32 12:1529-35. doi:10.1016/s0020-7519(02)00163-7.

15. van Wyk JA, Cabaret J, Michael LM. Morphological identification of nematode larvae of small ruminants and cattle simplified. Veterinary Parasitology. 2004;119 4:277-306. doi:10.1016/j.vetpar.2003.11.012.

16. Sweeny JPA, Robertson ID, Ryan UM, Jacobson C, Woodgate RG. Comparison of molecular and McMaster microscopy techniques to confirm the presence of naturally acquired strongylid nematode infections in sheep. Mol Biochem Parasitol. 2011;180(1):62-7. doi:10.1016/j.molbiopara.2011.07.007.

17. Roeber F, Jex AR, Campbell AJD, Nielsen R, Anderson GA, Stanley KK, et al. Establishment of a robotic, high-throughput platform for the specific diagnosis of gastrointestinal nematode infections in sheep. International Journal for Parasitology. 2012;42(13-14):1151-8. doi:10.1016/j.ijpara.2012.10.005.

18. Harmon AF, Williams ZB, Zarlenga DS, Hildreth MB. Real-time PCR for quantifying Haemonchus contortus eggs and potential limiting factors. Parasitol Res. 2007;101(1):71-6. doi:10.1007/s00436-006-0428-0.

19. Zarlenga DS, Chute MB, Gasbarre LC, Boyd PC. A multiplex PCR assay for differentiating economically important gastrointestinal nematodes of cattle. Vet Parasitol. 2001;97 3:199-209. 
20. Learmount J, Conyers C, Hird H, Morgan C, Craig BH, von Samson-Himmelstjerna G, et al. Development and validation of real-time PCR methods for diagnosis of Teladorsagia circumcincta and Haemonchus contortus in sheep. Vet Parasitol. 2009;166:3-4. doi:10.1016/j.vetpar.2009.08.017. 268 - 74.

21. Roeber F, Jex AR, Campbell AJD, Campbell BE, Anderson GA, Gasser RB. Evaluation and application of a molecular method to assess the composition of strongylid nematode populations in sheep with naturally acquired infections. Infection Genetics Evolution. 2011;11 5:849-54. doi:10.1016/j.meegid.2011.01.013.

22. Roeber F, Morrison A, Casaert S, Smith L, Claerebout E, Skuce P. Multiplexed-tandem PCR for the specific diagnosis of gastrointestinal nematode infections in sheep: an European validation study. Parasites Vectors 2017;10; doi:10.1186/s13071-017-2165-x.

23. Milhes M, Guillerm M, Robin M, Eichstadt M, Roy C, Grisez C, et al. A real-time PCR approach to identify anthelmintic-resistant nematodes in sheep farms. Parasitol Res. 2017;116(3):909-20. doi:10.1007/s00436-016-5364-z.

24. Roeber F, Jex AR, Gasser RB. Next-Generation Molecular-Diagnostic Tools for Gastrointestinal Nematodes of Livestock, with an Emphasis on Small Ruminants: A Turning Point? Advances in Parasitology, Vol 83. 2013;83:267-333; doi: 10.1016/b978-0-12-407705-8.00004-5.

25. ten Hove RJ, Verweij JJ, Vereecken K, Polman K, Dieye L, van Lieshout L. Multiplex real-time PCR for the detection and quantification of Schistosoma mansoni and S-haematobium infection in stool samples collected in northern Senegal. Trans R Soc Trop Med Hyg. 2008;102(2):179-85. doi:10.1016/j.trstmh.2007.10.011.

26. Roepstorff A, Nansen P. Epidemiology, diagnosis and control of helminths parasites of swine. FAO Animal Health Manual. 1998;3.

27. van Wyk JA, Mayhew E. Morphological identification of parasitic nematode infective larvae of small ruminants and cattle: A practical lab guide. Onderstepoort J Vet Res. 2013;80 1; doi:10.4102/ojvr.v80i1.539.

28. Reslova N, Skorpikova L, Slany M, Pozio E, Kasny M. Fast and Reliable Differentiation of Eight Trichinella Species Using a High Resolution Melting Assay. Scientific Reports 2017;7; doi:10.1038/s41598-017-16329-x.

29. Skorpikova L, Reslova N, Magdalek J, Vadlejch J, Kasny M. The use of high resolution melting analysis of ITS-1 for rapid differentiation of parasitic nematodes Haemonchus contortus and Ashworthius sidemi. Sci Rep. 2020;10 1; doi:10.1038/s41598-020-73037-9.

30. Rodríguez A, Rodríguez M, Córdoba JJ, Andrade MJ. Design of Primers and Probes for Quantitative Real-Time PCR Methods. PCR Primer Design. Methods in Molecular Biology. 2015;1275:31-56. doi:10.1007/978-1-4939-2365-6_3.

31. Mikel P, Vasickova P, Tesarik R, Malenovska H, Kulich P, Vesely T, et al. Preparation of MS2 Phage-Like Particles and Their Use As Potential Process Control Viruses for Detection and Quantification of Enteric RNA Viruses in Different Matrices. Frontiers in Microbiology 2016;7; doi:10.3389/fmicb.2016.01911.

32. Reslova N, Huvarova V, Hrdy J, Kasny M, Kralik P. A novel perspective on MOL-PCR optimization and MAGPIX analysis of in-house multiplex foodborne pathogens detection assay. Sci Rep. 2019;9 1:2719; doi:10.1038/s41598-019-40035-5.

33. Vadlejch J, Kopecky O, Kudrnacova M, Cadkova Z, Jankovska I, Langrova I. The effect of risk factors of sheep flock management practices on the development of anthelmintic resistance in the Czech Republic. Small Ruminant Research. 2014;117:2-3. doi:10.1016/j.smallrumres.2014.01.003. 183 90.

34. Santos LL, Salgado JA, Drummond MG, Bastianetto E, Santos CP, Brasil B, et al. Molecular method for the semiquantitative identification of gastrointestinal nematodes in domestic ruminants. Parasitol Res. 2020;119(2):529-43. doi:10.1007/s00436-019-06569-3.

35. Halvarsson P, Höglund J. Sheep nemabiome diversity and its response to anthelmintic treatment in Swedish sheep herds. Parasites Vectors 2021;14 1; doi:10.1186/s13071-021-04602-y.

36. Avramenko RW, Redman EM, Lewis R, Yazwinski TA, Wasmuth JD, Gilleard JS. Exploring the Gastrointestinal "Nemabiome": Deep Amplicon Sequencing to Quantify the Species Composition of Parasitic Nematode Communities. Plos One 2015;10 12; doi:10.1371/journal.pone.0143559.

37. Avramenko RW, Redman EM, Lewis R, Bichuette MA, Palmeira BM, Yazwinski TA, et al. The use of nemabiome metabarcoding to explore gastro-intestinal nematode species diversity and anthelmintic treatment effectiveness in beef calves. Int J Parasitol. 2017;47 13:893-902. doi:10.1016/j.ijpara.2017.06.006.

38. Vadlejch J, Kyrianova IA, Rylkova K, Zikmund M, Langrova I. Health risks associated with wild animal translocation: a case of the European bison and an alien parasite. Biol Invasions. 2017;19(4):1121-5. doi:10.1007/s10530-016-1306-z.

39. Kotrlá B, Kotrlý A, Koždoň O. Studies on the specifity of the nematode Ashworthius sidemi Schulz, 1933. Acta Vet Brno. 1976;45:123-6.

40. Moskwa B, Bien J, Cybulska A, Kornacka A, Krzysiak M, Cencek T, et al. The first identification of a blood-sucking abomasal nematode Ashworthius sidemi in cattle (Bos taurus) using simple polymerase chain reaction (PCR). Vet Parasitol. 2015;211(1-2):106-9. doi:10.1016/j.vetpar.2015.04.013.

41. van Doorn R, Klerks MM, van Gent-Pelzer MPE, Speksnijder A, Kowalchuk GA, Schoen CD. Accurate Quantification of Microorganisms in PCR-Inhibiting Environmental DNA Extracts by a Novel Internal Amplification Control Approach Using Biotrove OpenArrays. Appl Environ Microbiol. 2009;75 22:7253-60. doi:10.1128/aem.00796-09.

42. Kainz P, Schmiedlechner A, Strack HB. Specificity-enhanced hot-start PCR: Addition of double-stranded DNA fragments adapted to the annealing temperature. Biotechniques. 2000;28(2):278-82. doi:10.2144/00282st04.

43. Zhu KY, Clark JM. Addition of a competitive primer can dramatically improve the specificity of PCR amplification of specific alleles. Biotechniques. $1996 ; 214: 586$.

44. Stürzenbaum SR. Transfer RNA reduces the formation of primer artifacts during quantitative PCR. Biotechniques 1999;27 1:50; doi:10.2144/99271bm08.

45. Elmahalawy ST, Halvarsson P, Skarin M, Höglund J. Droplet digital polymerase chain reaction (ddPCR) as a novel method for absolute quantification of major gastrointestinal nematodes in sheep. Vet Parasitol. 2018;261:1-8. doi:10.1016/j.vetpar.2018.07.008. 
46. Berrie DA, East IJ, Bourne AS, Bremner KC. Differential recoveries from faecal cultures of larvae of some gastro-intestinal nematodes of cattle. J Helminthol. 1988;62(2):110-4.

47. Weerakoon KG, McManus DP. Cell-Free DNA as a Diagnostic Tool for Human Parasitic Infections. Trends in Parasitology. 2016;32 5:378-91. doi:10.1016/j.pt.2016.01.006.

\section{Figures}

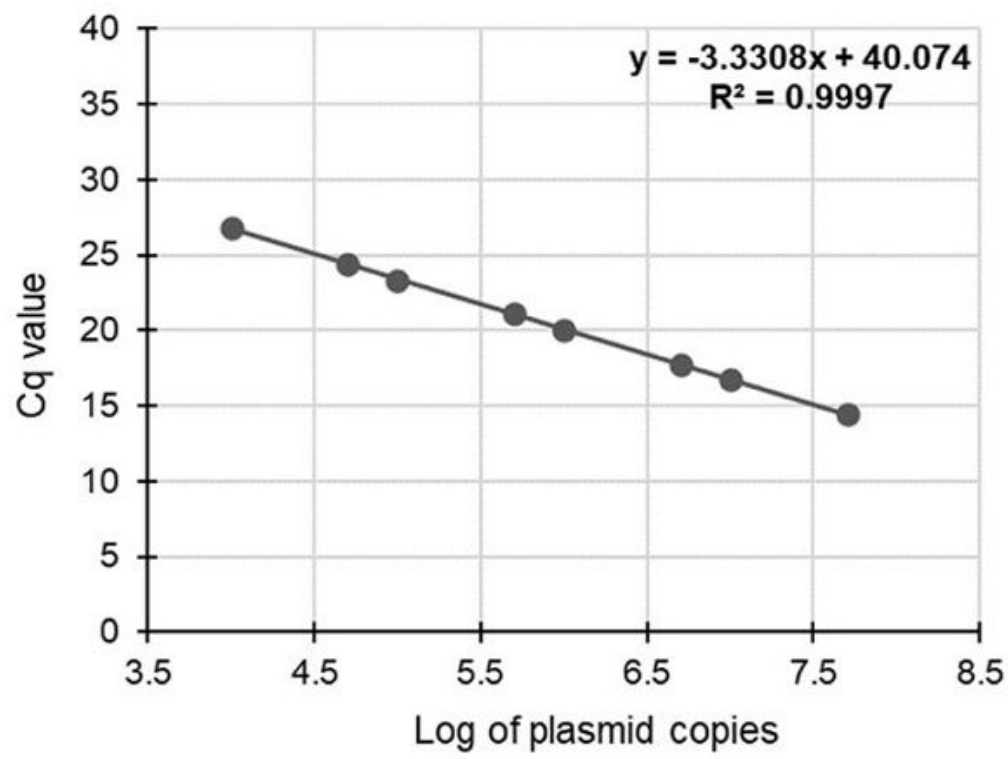

Figure 1

A calibration curve of $\mathrm{H}$. contortus ITS2 plasmid standard. The data points are the median of three replicates. The equation and R2 linearity value resulting from the linear regression analysis are shown in the graph.

A)

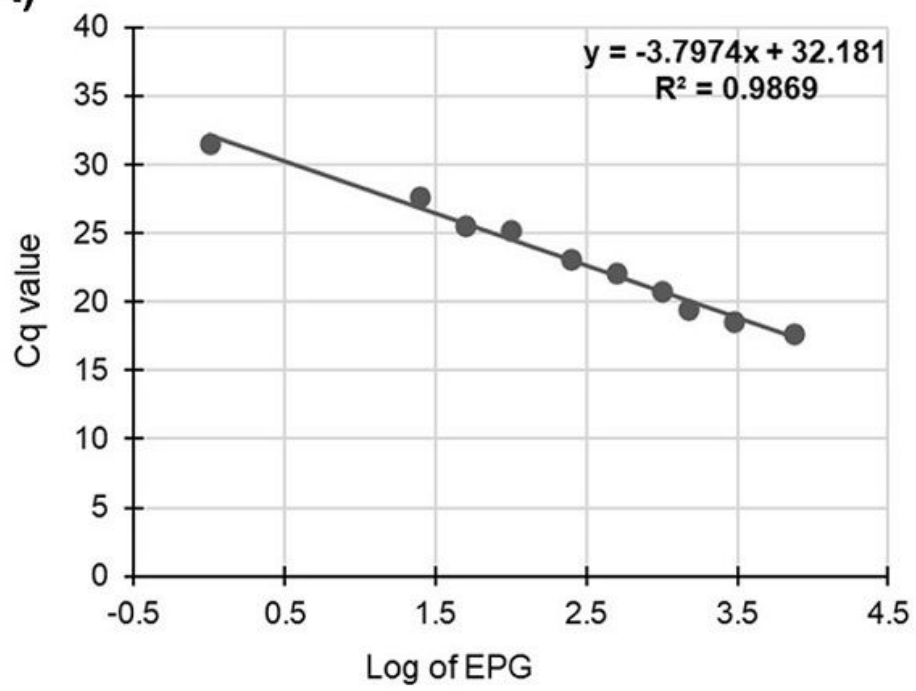

B)

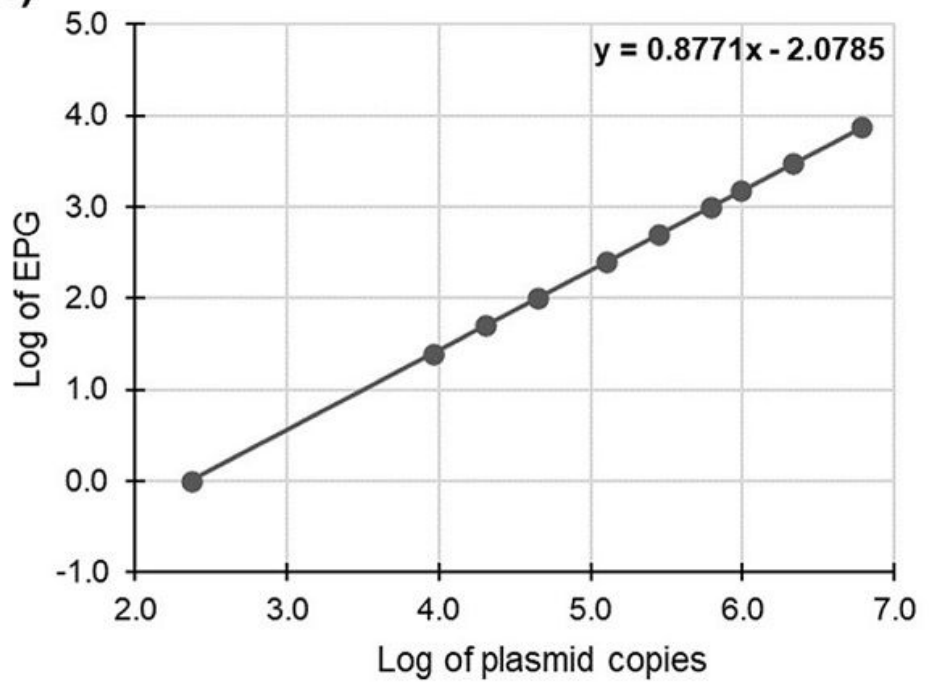

Figure 2

A semi-quantitative estimation of the number of eggs in unknown samples. A) A calibration curve of faecal concentration series ranging from 7,500 to 1 EPG. The data points are the median of three replicates of two independently diluted series. The equation and R2 linearity value resulting from the linear regression analysis are shown on the graph. B) The formula serves to convert plasmid copy numbers to EPG and was created by assignment of plasmid standard copy numbers to corresponding EPG counts correlated based on faecal concentration series.

\section{Supplementary Files}

This is a list of supplementary files associated with this preprint. Click to download. 
- ReslovaGraphicalAbstract.png

Page 15/15 